\title{
Deliberation and Collaboration in the Policy Process: A Web 2.0 approach
}

\author{
Klaus Petrik \\ The School of Social Work and Human Services, Level 3, Chamberlain Building, The University of Queensland, St Lucia \\ QLD 4072 Australia, Author Contact, Affiliation, Address, klaus.petrik@uqconnect.edu.au, +61 733652068
}

\begin{abstract}
This paper is a summary of a PhD thesis proposal. It will explore how the Web 2.0 platform ${ }^{1}$ could be applied to enable and facilitate the large-scale participation, deliberation and collaboration of both governmental and nongovernmental actors in an $\mathrm{ICT}^{2}$ supported policy process. The paper will introduce a new democratic theory and a Web 2.0 based e-democracy platform, and demonstrate how different actors would use the platform to develop and justify policy issues.
\end{abstract}

Keywords: E-democracy, Web 2.0, civic engagement, deliberative democracy, participatory decision-making (policy cycle), proxy voting, collective intelligence $(\mathrm{Cl})$

Acknowledgement: This is a republication of a peer-reviewed conference paper. It is listed in the proceedings of the 2009 Conference on Electronic Democracy at the University of Economics and Business Administration, Vienna, Austria.

$\mathrm{T}$

he discussion about what democracy should mean and the appropriate degree of citizens' participation in the actual policy process is age old. Democratic theory knows a broad variety of theories reaching from classical Athenian democracy, republicanism, Marxist viewpoints, participatory democracy and modern liberalism. According to Held (2004), all those forms but one can be divided into two broad types: Direct or participatory democracy on the one side and liberal or representative democracy on the other (p. 4). The model that doesn't seem to fit either side "Deliberative democracy" emerged just in the 1980es. It is a variant that seeks to justify political decisions in a process that involves free and equal citizen in deliberations on issue. Deliberative thinkers argue that the quality of decision-making should be at the centre of public debate, that political rationality is inseparable from the idea of justification to others, and that the strengthening of discursive rationality is vital to the search for the best substantive solutions to collective problems (p. 205). Although deliberative democrats such as Jürgen Habermas, John Dryzek, or James Fishkin inspired political thinking, they could not unsettle the predominant liberal representative order. The emergence of the Internet at the end of the 20st century winged new hope for the deliberative ideal, but back then the e-democracy paradigm of the early-mid 1990s set too high expectations for that time. It assumed that the 'creation of deliberative spaces', particularly discussion forums, would 'provide for rich, critical, self-reflective, tolerant and sustained citizen engagement', allowing citizens to 'deliberate free from the constraints of time'. These very demanding expectations have however proven 'notoriously difficult to embed in political organizations' as the participation rates of initial e-democracy projects remained modest during the

\footnotetext{
${ }^{1}$ Chang \& Kannan (2008) describe the Web 2.0 platform as a networked world that supports individual users creating content individually and collectively, sharing and updating information and knowledge using sophisticated, diverse sharing devices and tools, and remixing and improving on content created by each other.

${ }^{2}$ Information and Communication Technology
} 
era of "Web 1.0" (Chadwick, 2008). But now at the beginning of the 21st century this age old discussion need to involve a new variable: The Web 2.0 platform and the emerging social web.

In the following this paper will present a new ICT based democracy model which utilizes the Web 2.0 platform to involve governmental and non-governmental actors in a process of deliberation and collaboration on policy issues. At this stage in the research this model could be described as 'Deliberative-Collaborative e-Democracy', as it involves practices and components of e-democracy, participatory democracy, representative democracy and deliberative democracy. Its key component is a Web 2.0 based e-democracy platform that enables and facilitates the development and justification of decisions in the process of policy making.

After highlighting its theoretical backgrounds and preconditions, the paper will introduce the model of 'Deliberative-Collaborative e-Democracy'. It will demonstrate a Web 2.0 based edemocracy platform and an algorithm for policy making and show how citizens would apply its components to resolve policy problems and to achieve policy goals. The article concludes with a brief summary of the expected benefits of the decision system.

\section{From Web $\mathbf{1 . 0}$ to Web 2.0}

The terms Web 1.0 and Web 2.0 describe stages of development of the World Wide Web. This section provides a personal interpretation of the meaning of that development.

Web 1.0 describes the traditional, single-sided one-to-many method of browsing information online. The content creator, usually the website administrator acts as sender and provides data to a multitude of Internet users. The recipients play thereby a rather passive role as they have no direct influence on the content creation and distribution.

In this regard the "institutional approach" mirrors the old-established pattern of how businesses and governments provide goods and (public) services to their "recipients": the primary say of customers in commercial production lies in the opportunity to choose between different goods and services; the primary say of the citizenry in liberal-democratic governance lies in its right to vote between different representatives during periodical elections. These preferences can influence the production and behavior of businesses and governments just indirectly.

In contrast to that, Web 2.0 is a "collaborative" approach that gives Internet users an active role in the content creation and distribution. According to Chang \& Kannan (2008) users become coproducers of content and information rather than being just consumers. They describe Web 2.0 as network platform that allows high levels of user interactions that result in content and updates that are in a "permanent beta" stage as they constantly evolve, and that this in turn enables rich user experiences that go much beyond the Web 1.0 era. It is thus not just a technological but a social advancement. One of its most established realizations, the Wikipedia platform, describes Web 2.0 in its identically named article as a 'second generation of web development and design' that has 'led to the development and evolution of web-based communities, hosted services, and applications; such as social-networking sites, video-sharing sites, wikis, blogs, and folksonomies'.

\section{Democracy and Web 2.0}

So what could democracy mean in the advancing communication age? Every population, state and territory has individual social, cultural and environmental characteristics which are subject to constant change. New developments, unpredictable events and "wicked problems" such as economic downturns, pandemics, or political crises require the investigation, deliberation and cooperation of many stakeholders as they often do not involve a simple "one-fits-all" solution (cf. Roberts, 2000). Such as Macmillan \& Hughes (2008) I argue that static systems of government with rigid power structures and regulations are neither eligible to address such political challenges, nor further necessary. The latest developments in ICT and Web 2.0 enable not just large-scale participation but facilitate a meaningful collaboration of those who are willing to contribute. Citizens should have easy access to all information that is available and relevant to the policy process 
(transparency), and thereupon determine their individual degree of involvement. Those who are willing to contribute directly should be facilitated to do so according to their individual skills, experiences, and preferences. Those who seek to be represented should be facilitated to find the ideal representatives and to vote them directly into the different policy domains, and to determine certain tasks and responsibilities for each of them.

Despite the fact that the political engagement and the participation rates of citizens in the existing e-democracy practices have been moderate so far (Chadwick, 2008) I suggest that this might be changing with the maturation of the Web 2.0 platform. The fast increasing engagement of people in social networks, co-production environments, and information sites such as Facebook, Google, Youtube or Wikipedia entails the emergence of a networked citizenry with a dynamic and convenient access to a fast growing stock of knowledge and information, and multiple tools for reediting, re-distributing, and inter-exchanging these data among each other. The readiness and qualification of such a "networked information society" (Castells, 2000; Breit \& Servaes 2005) to contribute to the policy process may rise significantly if it would be open and accessible over the Web 2.0 platform. (cf. Sanson, 2008)

If Web 2.0 implies a movement of control over a website's content creation from an administrator to the Internet users (Chang \& Kannan, 2008) I suggest that the application of Web 2.0 on the level of governance could imply a shift of control over its output (policies, laws; public services) from the established authorities (political institutions, parties, departments) to its customers (citizenry). The development from the above described "institutional approach" of the Web 1.0 era to the "collaborative approach" of the emerging Web 2.0 era could hereby inspire the transformation from a representative system with a passive electorate to a deliberative-collaborative e-democracy, in which citizens are granted various options for participation. In this regard the term "e-democracy" does not simply refer to the utilization of new technologies for established political practices (cf. Parvez \& Ahmed, 2006), but to a new kind of democracy itself which functioning is based on these new technologies. (cf. Macmillan \& Hughes, 2008)

\section{Deliberative-Collaborative e-Democracy}

Deliberative-Collaborative e-Democracy is a normative policy model that is based on contemporary ICT and Web 2.0 developments. Its aim is to increase the quality of policy making by involving the entire electorate directly and/or indirectly (see proxy representation) in a collaborative policy process (see below), and to generate "ideal public policies" which have following characteristics: * "Fact-regarding, i.e. responding to common problems (e.g. financial crises) and/or collective goals (e.g. price stability); * Other-regarding, i.e. assessed and justified by a large amount of free and equal citizens; and * Future-regarding, i.e. perceived as "positive" or "satisfying" by these citizens in the short and long run after implementation (cf. Held 2004, chapter 9). In order to approach "ideal policies" all stakeholders (governmental ${ }^{3}$ and non-governmental ${ }^{4}$ ) are perpetually involved in a policy process that is implemented as Web 2.0 software on a public web server. This process requires each policy to pass through four steps: (1) Suggestion of ideas and/or strategies, (2) Collaborative rating and evaluation of the suggestions, (3) Collective decision-making upon the options, and (4) Collective evaluation of the outcome after their implementation (cf. the Australian policy cycle as defined by Bridgman \& Davis, 2004)

Following the tradition of Held's (2004) democracy modelling, I now want to introduce the sum model for Deliberative-Collaborative e-Democracy. It is based on a Web 2.0 internet platform that enables large scale information, collaboration and representation in the described process.

\footnotetext{
${ }^{3}$ I.e. public servants, politicians; political institutions like parties, departments, bureaus, etc

${ }^{4}$ I.e. common people/citizens; commercial and non-commercial civic institutions like corporations, NGOs, lobbies, unions, etc
} 


\section{Principle(s) of justification}

Political decisions that may affect a multitude of citizens must be evaluated and justified by a multitude of citizens before implementation ${ }^{5}$. The Web 2.0 platform provides therefore a functional, convenient, and efficient, framework for collaborative political assessment, deliberation, and justification. The policy process provides to the individual citizen various modes of direct participation and representation, for which a large variety of freely selectable domain experts, politicians and parties are available.

Key features (i.e. the key components of the e-democracy platform; see next chapter for details) Suggestion system: A web server for suggesting (new) policy issues

Lobby group system: A social networking service that enables distributed citizens to converge and collaborate on common issues or interests independent from location and time

Policy wiki: A wiki server on which the policy issues are particularized

E-discussion forum: An open online forum for the deliberation upon policy issues

Evaluation system: A Web 2.0 framework for the mutual evaluation of policy strategies

Decision-making system: An online platform for voting upon evaluated policy strategies

Proxy representation system: A Web 2.0 framework to delegate representatives

General conditions (i.e. preconditions for the e-democracy platform)

E-Authentication: A distinct procedure authenticates the citizens in the e-democracy system to safeguard the transaction of legally entitled citizens exclusively. (cf. Steward, 2009)

E-Readiness \& e-Inclusion: The majority of the entitled citizenry has access to, and is able to use the ICT infrastructure and the collaborative tools provided by the e-democracy system. For those citizens who do not have an own access to the Internet, free public Internet cafés and wireless areas are available to provide a secure access to the e-democracy platform. Those who do not fulfil the condition of e-inclusion (e.g. for cultural, educational, or age-related reasons) can choose between conventional methods of either full representation (e.g. through voting a political party in a booth or per post) or of direct participation (e.g. paper petitions) until the digital divide is concluded. (cf. Huber 2007)

- Direct democracy: The implementation of the decision-making system would require two direct democratic procedures to be enshrined in the institutional design of a political system: (a) the (popular) initiative, i.e. the right of a specified number of citizens to propose a petition to the entire electorate; and (b) the popular (referendum) vote, a procedure in which the electorate decides upon the implementation of a formally adopted petition. (cf. Huber 2007)

\section{Components of the e-democracy platform}

This section will explain the key components of the e-democracy platform and its main functions.

\subsection{Suggestion system}

The suggestion system is a public database that collects political suggestions and ideas and assesses for each the degree of civic agreement. It enables governmental actors and citizens to propose policy problems, goals, strategies, and/or political candidates for a mutual review through other stakeholders. Submitted petitions become items in a list; each refers to a public domain, either regionally, nationally or internationally. Other actors can access these lists online and determine the hierarchy of the items through ranking: The proponents (e.g. the supporters of a suggestion) can rank an item up, and the opponents rank it down. As a result, the suggestion with

\footnotetext{
${ }^{5}$ cf. "quod omnes tangit, ab omnibus approbetur" from the ancient Roman law
} 
the most proponents (and least opponents) appears on the first rank of each domain; and vice versa, those with the most opponents (and least proponents) on the least. The highest ranked proposals proceed to the evaluation system which is the next level of the policy process (see below). The aim of the suggestion system is to enable not just established political institutions, but also minorities to propose their concerns to a larger part of the electorate. Both proponents and opponents of a petition can form a lobby group (see below). (cf. Google Moderator: An onlineservice that uses "crowdsourcing" to rank user-submitted questions to policy makers)

\subsection{Lobby group (network)}

The second key component is a social network service for political purposes. Such as Facebook this service enables and facilitates the convergence and collaboration of interest groups and likeminded people (such as the proponents of a petition) and provides Web 2.0 tools for their communication, organization, strategy, and decision-making. In a group profile a lobby group can express its political viewpoints, agenda, and key arguments. Within the social network individual groups can cooperate with each other, merge and/or split up. The social network service integrates not just all established institutions (such as NGOs or political parties) as groups, but to enables the civil society to form ad-hock (pressure) groups (e.g. to focus on issues that are not jet covered by the established institutions). It therefore empowers distributed stakeholders (e.g. a minority) to converge and develop their common concerns autonomously and independent from the constraints of space and time. Lobby groups can take over a representative function for other stakeholders (see proxy representation) and/or form a new political party (if they fulfil the required requirements). According to the number of members and supporters they can initiate political debates (see ediscussion forum), policy wikis, or apply the evaluation system for their issues. (cf. Shim \& others 2002: Group support systems; Sanson, 2008)

\subsection{E-Discussion forum}

The e-discussion forum is the place for public online deliberation. It confronts the proponents and the opponents of a policy issue directly into a discussion. Every participant can ask or answer questions, make comments, give feedback, or call for ad-hoc polls on discussion issues. The aim of the e-discussion forum is to facilitate and encourage a factual, thorough, and consensus oriented discussion upon policy issues, and to minimize the influence of demagogy and populism: * In order to straighten out unscientific and unjustifiable arguments of individual panellists each forum discussion is supervised by professional domain experts (e.g. researchers); ${ }^{*}$ in order to counterbalance the potential bias of overrepresented and polarized lobbies, proxy representatives represent the indifferent society in the forum (see proxy representation); ${ }^{*}$ in order to maximize the systems transparency and to facilitate later reviews all discussions are automatically recorded and archived. The openness of the online forum seeks to avoid the screening of certain topics, stakeholders, or information as it can be done by individual authorities of mass media providers. By mutually ranking the contributors and their contributions, the majority of panellists determine autonomously the relevancy of discussion contents. The forum provides internal polls to the panellists in order to consent on certain issues or make petitions to other actors. An example: Through the aggregation of signatures the forum panellists can encourage important actors (e.g. politicians) to participate in the discussion or to comment on discussion issues. Thus, it becomes awkward for key personalities to ignore unpleasant questions, affairs or stakeholders. (cf. Fishkin, 1991: Deliberative polls; Proceedings of "The public sphere project")

\subsection{Policy Wiki}

The policy wiki facilitates the actors to particularize policy issues collaboratively. A wiki is a cocreated online document that provides general information and web links for each policy issue. A new wiki can be initiated and edited by authenticated citizens and institutions. Such as the forum it involves the proponents and opponents of an issue as well as experts and the indifferent society. In 
contrast to the forum, in which individual standpoints and arguments are discussed, a policy wiki provides factual information such as survey results or hard facts. An ideal wiki article comprises following components: Title (e.g. The Australian financial crises); Relevant policy domain(s) (e.g. finance, economy); A brief definition and summary of the policy issue at the beginning of the article; The status of the issue in the policy cycle; Detailed information (text, graphics, tables, photos, audio, or video material, etc.); A contraposition of the perspectives of the proponents and opponents of the issue; The findings of the forum discussion; Information about the participators and their contributions; Links and references to * related wikis and entries in the constitution or law, * external information and learning resources, * data records of previous policy cycles, such as data achieves of speeches, discussions, commends, suggestions, etc. Complex issues are hereby simplified for the comprehension of non-experts. In summary all wikis are interconnected to a "policy encyclopaedia" that will cover all political domains eventually. This framework serves as ultimate source of factual co-created political information (in contrast to political campaigns and information provided by the mass media) and strives to support "informed decisions" (see below). (cf. http://policywiki.theglobeandmail.com)

\subsection{Evaluation System}

The evaluation system is a collaborative online analysis tool. It imports the highest-ranked petitions from the suggestion system and prepares each for a mutual assessment through the stakeholders in order to get relevant information for their final decision. The system conducts an online survey for which it addresses the population as research panel (cf. deliberative polls; Fishkin, 1991). It compromises two steps: In step one domain experts (such as analysts, professionals, or politicians) determine the upsides and downsides for each suggested strategy, i.e. the different effects and consequences that it may have on the state, economy and the people. In step two the citizenry is asked to determine in what way and to what degree each individual feels affected by each of these consequences. This questionnaire provides the decision-makers with a preview on the potential impact of each evaluated strategy (e.g. on minority groups or other domains) and encourages them to vote responsible and in the sense of the whole society ("fact regarding", "future regarding" and "other regarding"; see Held, 2004; p. 232). The evaluation system is applied a second time in the fourth step of the policy cycle, i.e. after the implementation of a strategy in order to evaluate its success. (cf. Shim \& others, 2002)

\subsection{Decision-making system ${ }^{6}$}

The decision-making system is the online voting component of the e-democracy platform through which the stakeholders make final decisions about previously evaluated policies. By means of a popular vote (referendum) they decide upon the implementation of new laws or collective actions (self-government). As this is the only component with decisive executive and legislative power it needed to be implemented as direct democratic procedure in the institutional design of the political system (cf. Huber 2007). Such as the other components this system provides two ways of participation to the electorate: (1) direct, by attending e-votes in person, or (2) indirect, by delegating a proxy to vote on one's behalf (see proxy representation). (cf. Green-Armytage; Shim \& others 2002: Decision-making process; IRI 2008, p. 233: Consensus Democracy)

\section{Collective Learning and Intelligence}

In the described process the electorate is confronted with the outcome of its own decisions. Therefore the e-policy cycle can be seen as collective feedback loop or a learning cycle through which the people can gradually improve their decision-making skills. This characteristic should stimulate the awareness and responsibility of the public for its behaviour. Through the ongoing

\footnotetext{
${ }^{6}$ The explanation of the actual voting process and how the security issues are taken care of would break the mould of this paper. For questions referring to this issue please contact the author.
} 
processes of collective observing, suggesting, commenting, ranking, deliberating, evaluating, voting, revising and adjusting through multiple stakeholders the e-democracy platform would utilize the wisdom and collective intelligence of a nation. That is a shared group intelligence that emerges from the collaboration, competition, and consensus decision-making of its constituents (cf. Wikipedia: "Collective Intelligence"; Surowiecki, 2004)

Collaboration: In order to bring a policy issue into public awareness, its initiators have to cooperate with their supporters. As the collaboration between experts and common people would rather be upon shared problems, common ideas, and political goals it may be more cohesive and efficient than the collaboration based on party affiliation.

Competition: In order to be considered for implementation, policy suggestions compete with each other as they go through the decision process from ranking, evaluating, and voting. Competition occurs hereby however rather be between issues than between people or institutions, which become less relevant in the process.

Consensus decisions: The increased level of available information and the transparency of the process seeks to generate consensus decisions; either by modifying decisions so that most stakeholders agree or by encouraging actors to relinquish a certain benefit in order to protect the interests of a minority or to achieve a higher goal. (cf. IRI 2008, p. 233: Consensus Democracy)

\section{Proxy representation}

The aspects of direct participation of the suggested e-democracy platform require the citizens to engage in tasks that are usually conducted exclusively by professional governmental authorities. Although the tools and components of the platform facilitate contribution, these tasks would overburden the knowledge, time, and disposition of many citizens. To address this problem the platform provides a final component: The proxy representation system allows each citizen to defer certain or even all the participatory tasks to free selectable proxy representatives. Every actor who is willing to take over the tasks of others becomes a proxy representative and the represented persons their principals. A proxy could be a trusted person or institution such as an educated friend, a domain expert, a certain politician, a political party, or a lobby group (cf. Yamakawa, 2007). An important task of proxies would be to counterbalance the overrepresentation of polarising lobbies in the individual components by representing the indifferent actors there. Proxy representation would be available for all participatory tasks in all stages of the policy cycle. In the individual proxy settings of the e-democracy system each citizen could specify for which tasks and in which policy domain he/she wishes to be represented by which proxy. Proxies could be delegated just for the preparation of decisions (i.e. making and ranking suggestions, contributing to the political debates and wikis; evaluating strategies and policies etc.), or for the actual decisionmaking as well (i.e. attending the popular votes). If a citizen chooses to delegate a proxy to decide in a popular vote on his/her behalf the proxy adds the weight of his principal's vote to his own one. He can then choose to vote directly or name a further proxy to vote on his behalf. Hereby the second proxy accumulates the voting power of the first one and his principal (proxy chain). There is no limit on the number of representatives who can serve at a given time. The principals (citizens) retain the right to change their proxy or vote autonomously at any time before the vote. If a principal changes his mind in the last moment and wants to vote directly, his/her vote will override the one which is casted through the proxy chain. Each citizen could scale his/her individual degree of participation between no representation (i.e. total political autonomy) and full representation according to his/her individual skills, experiences, and preferences. In the second case one or more representative or institution would take over all participatory tasks in all policy domains such as in liberal democracy. Because of this characteristic the proxy system bridges the gap between direct participation and representation; and therefore combines the best features of direct democracy and representative democracy (cf. Green-Armytage). The e-democracy platform would collect and display performance data of each proxy in order to facilitate the principals in finding the appropriate representation. This statistical data as well as feedback from other principals would be 
available on the personal profile of each proxy. This would highlight the domains in which the proxy is available, the number of principals that he/she represents, the experience (i.e. the number of suggestions, rankings, evaluations, contributions to debates and wikis etc.) as well as his/her decision-making efficiency (i.e. the percentage of strategies suggested/voted by the proxy that have achieved a policy goal after implementation). Through proxy delegation the electorate could vote representatives directly into the different governmental domains and positions (departments). If for example a majority of citizens would appoint a skilled expert as proxy for the decision-making in the domain 'infrastructure', he or she would become the decisive authority in this domain ("infrastructure minister"). The other proxies in this domain would thereby form an opposing force. The difference to a liberal government is that principals (in contrast to voters) can substitute their representatives at any time and that they retain the right to vote directly on an issue if necessary (e.g. to resolve a conflict). Therefore the system limits the power of the authorities and calls them to a high accountability for their actions.

\section{Introducing the new system}

The problem with the introduction of the new e-democracy system is not only technology, but the readiness of the societies and their governments to adopt the new system and to use it in a meaningful way. Therefore the implementation would require a transition period with strong civic education programs in politics, ICT and online collaboration. Especially the people in traditionally representative systems needed to be encouraged to participate in order to gather experience and skill in political decision-making. Besides that the platform could be implemented in modern liberalrepresentative and direct democratic countries. Components such as the suggestion system, the social network service, the discussion forum, the policy wiki, and the evaluation system alone have a purely informational and analytical function, but no decisive political power. They could be utilized in representative systems without the necessity to amend its institutional design. In this situation, the representative government could utilize the data from the platform (suggestions, evaluations, deliberations) such as the data from traditional political opinion polling without being obliged to implement any of these policies. A direct democratic country (such as Switzerland) on the other side may already provide an institutional design with popular initiatives and referendum vote procedures. This would give principled room for the implementation of the decision-making system. As the collaborative policy process as it is described in this paper would enable a new form of selfgovernment it needed to be implemented cautiously, e.g. by initially just applying it for issues of minor relevance and complexity, and by increasing its range of application just in these areas where a meaningful outcome was achieved. ("Radical transformative deliberative participatory democracy" cf. Held 2006, p. 253)

\section{Conclusion}

Such as Web 2.0 has changed the principle of the creation of website content in a relatively short period of time it could similarly change the way of how governments function. The collaborative, autodidact, and self-regulatory patterns that can be observed on the established Web 2.0 platform could hereby similarly increase the quality and performance of governance while saving public spending (cf. Macmillan \& Hughes, 2008). The presented collaborative policy process could provide a new perspective on Abraham Lincoln's definition of democracy as "government of the people, by the people and through the people". If implemented successfully it would not just be beneficial in various ways but could also solve a variety of common problems related to governance:

- The "e-policy process" would be transparent and accessible for all citizens (vs. corruption). The civic inclusion may stimulate the citizens' interest, knowledge, and willingness to participate in politics (vs. voter apathy). (cf. Barber, 1984; Dryzek, 2000; Fishkin, 1991) 
- The collaborative process would engage the people in a perpetual online research panel with a high sample size. This panel may produce remarkably efficient political, economical and social predictions regarding the future (Wisdom of the crowd, cf. Surowiecki, 2004).

- Influential commercial lobbies (e.g. from industry and finance) needed to justify their political interests and suggestions in front of the entire electorate and not just in front of a relatively small group of governmental officials (justice; vs. manipulation).

- The proxy system may accomplish equal opportunities for all citizens to take over political functions, independent from the financial status, physical appearance, race or gender (equality of opportunities). Proxy representatives would become fully accountable for their decisions as these would be recorded electronically. If the electorate is not satisfied with certain decisions it could dismiss individual representatives and leave the rest of the government untouched (stability). As many people would be involved in proxy delegation, patronage, nepotism, and similar corruption would become more difficult. Besides, the cost of elections and political campaigns could be saved and applied elsewhere. (cf. Green-Armytage; Barber, 1984)

\section{References}

Barber (1984). Strong Democracy: Participatory Politics for a New Age. Berkeley, CA: University of California Press Breit \& Servaes (2005). Information Society or Knowledge Societies UNESCO in the Smart State. University of Queensland Bridgman, P., Davis, G. (2004). The Australian Policy Handbook. $3^{\text {rd }}$ edition. ALLEN \& UNWIN

Castells (2000). The rise of the network society. Wiley-Blackwell

Chadwick, A. (2008). Web 2.0: New Challenges for the Study of E-Democracy in an Era of Informational Exuberance. Department of Politics and International Relations/New Political Communication Unit, Royal Holloway, University of London.

Chang, A., Kannan, P.K. (2008). Leveraging Web 2.0 in Government. University of Maryland. IBM Center for The Business of Government. Retrieved July 07, 2009, from www.businessofgovernment.org

Dryzek, John S. (2000). Deliberative Democracy and Beyond. Liberals, critics, contestations. Oxford University press

Fishkin, James S. (1991). Democracy and Deliberation: New Directions for Democratic Reform. New Haven, CT: Yale University Press

Green-Armytage, J. (2009). Direct Democracy by Delegable Proxy. Retrieved July 07, 2009, from http://fc.antioch.edu/ james green-armytage/vm/proxy.htm

Habermas, Jurgen (1989). The Structural Transformation of the Public Sphere. Cambridge, MA: MIT Press;

Held, David (2006): Models of Democracy. Third edition. Polity press

Huber, A. (2007). E-Democracy in a participatory form of democracy (direct democracy). Sofia CAHDE. Retrieved July 07, 2009, from www.bmeia.gv.at/fileadmin/user upload/bmeia/media/AOes/eDemocracy/4101 06 edemo in a direct demo.pdf

IRI - Initiative \& Referendum Institute Europe (2008). Guidebook to Direct Democracy in Switzerland and beyond. 3rd edition

Macmillan, P., Medd, A., Hughes, P (2008). The future of collaborative government and Web 2.0. Deloitte. Retrieved July 07, 2009, from http://www.deloitte.com/dtt/article/0,1002,cid\%253D208669,00.html

Parvez \& Ahmed (2006). Towards an Integrated Perspective on e-Democracy. Information, Communication \& Society Vol. 9, No. 5, October 2006, pp. 612-632

Roberts, N. (2000). Wicked Problems and Networked Approaches to Resolution. International Public Management Review, 1(1), 2000.

Sanson, A. (2008). Facebook and Youth Mobilization in the 2008 Presidential Election. Gnovis journal 2008, Volume 8/No. 3

Shim J.P., Warkentin M., Courtney J., Power D., Sharda R., Carlsson C. (2002). Past, present, and future of decision support technology. Elsevier Science B.V. PII

Steward, A. (2009). National e-Authentication Framework. Department of Finance and Deregulation. Australian Government Information Management Office 
Surowiecki, J. (2004). The Wisdom of Crowds. New York: Random House.

The public sphere project (2009). Retrieved July 07, 2009, from http://publicsphereproject.org/events/diac08/proceedings/index.html

Yamakawa, H., Yoshida, M., Tsuchiya, M.(2009). Toward Delegated Democracy: Vote by Yourself, or Trust Your Network; International Journal of Human and Social Sciences 1;2; Spring 2007. Retrieved July 07, 2009, from www.waset.org 